\title{
Numerical investigation and estimating correlation of micromixing performance of coaxial mixers
}

\author{
Baoqing Liu ${ }^{1,2, *}$, Ning Sun ${ }^{1}$, Zhijiang Jin ${ }^{1}$, Yikun Zhang ${ }^{1}$, Bengt Sunden ${ }^{2, *}$ \\ (1. Institute of process equipment, Zhejiang University, Hangzhou 310027, China \\ 2. Department of Energy Sciences, Lund University, SE-22100 Lund, Sweden)
}

\section{Corresponding Author:}

Baoqing Liu, Email: baoqingliu@zju.edu.cn

Bengt Sunden, Email: bengt.sunden@energy.lth.se 
Table S1 Experimental results and predicted values of segregation index (PBT+RT+anchor)

\begin{tabular}{cccccccccc}
\hline$D i$ & $D$ o & $N$ i & $N$ o & $l$ & $C$ & $\mu$ & $\rho$ & $X_{\text {s,exp }}$ & $X_{\text {s, pred }}$ \\
\hline 200 & 340 & 60 & 10 & 300 & 180 & 1 & 1408 & 0.405 & 0.422 \\
200 & 340 & 80 & 10 & 300 & 180 & 1 & 1408 & 0.346 & 0.333 \\
200 & 340 & 100 & 10 & 300 & 180 & 1 & 1408 & 0.293 & 0.278 \\
200 & 340 & 120 & 10 & 300 & 180 & 1 & 1408 & 0.241 & 0.240 \\
200 & 340 & 150 & 10 & 300 & 180 & 1 & 1408 & 0.212 & 0.202 \\
\hline 200 & 340 & 60 & 10 & 390 & 180 & 1 & 1408 & 0.469 & 0.491 \\
200 & 340 & 80 & 10 & 390 & 180 & 1 & 1408 & 0.445 & 0.388 \\
200 & 340 & 100 & 10 & 390 & 180 & 1 & 1408 & 0.433 & 0.324 \\
200 & 340 & 150 & 10 & 390 & 180 & 1 & 1408 & 0.371 & 0.235 \\
\hline 200 & 340 & 80 & 10 & 300 & 180 & 1.5 & 1425 & 0.495 & 0.586 \\
200 & 340 & 100 & 10 & 300 & 180 & 1.5 & 1425 & 0.487 & 0.489 \\
200 & 340 & 120 & 10 & 300 & 180 & 1.5 & 1425 & 0.441 & 0.423 \\
200 & 340 & 150 & 10 & 300 & 180 & 1.5 & 1425 & 0.401 & 0.354 \\
\hline 200 & 340 & 100 & 10 & 300 & 180 & 1 & 1408 & 0.2933 & 0.278 \\
200 & 340 & 100 & 15 & 300 & 180 & 1 & 1408 & 0.289 & 0.280 \\
200 & 340 & 100 & 20 & 300 & 180 & 1 & 1408 & 0.276 & 0.284 \\
\hline 96 & 340 & 100 & 10 & 300 & 180 & 1 & 1408 & 0.481 & 0.586 \\
96 & 340 & 120 & 10 & 300 & 180 & 1 & 1408 & 0.423 & 0.513 \\
96 & 340 & 150 & 10 & 300 & 180 & 1 & 1408 & 0.392 & 0.435 \\
96 & 340 & 180 & 10 & 300 & 180 & 1 & 1408 & 0.340 & 0.380 \\
96 & 340 & 200 & 10 & 300 & 180 & 1 & 1408 & 0.292 & 0.351 \\
\hline 133 & 340 & 100 & 10 & 300 & 180 & 1 & 1408 & 0.351 & 0.434 \\
133 & 340 & 120 & 10 & 300 & 180 & 1 & 1408 & 0.315 & 0.378 \\
133 & 340 & 150 & 10 & 300 & 180 & 1 & 1408 & 0.271 & 0.318 \\
\hline 160 & 340 & 60 & 10 & 300 & 180 & 1 & 1408 & 0.408 & 0.539 \\
160 & 340 & 80 & 10 & 300 & 180 & 1 & 1408 & 0.355 & 0.428 \\
160 & 340 & 100 & 10 & 300 & 180 & 1 & 1408 & 0.298 & 0.359 \\
160 & 340 & 120 & 10 & 300 & 180 & 1 & 1408 & 0.254 & 0.311 \\
160 & 340 & 150 & 10 & 300 & 180 & 1 & 1408 & 0.212 & 0.261 \\
\hline
\end{tabular}

